\title{
IMPLEMENTATION SCHEME OF AGRICULTURAL CONTENT MANAGEMENT SYSTEM
}

\author{
Xianfeng $\mathrm{He}^{1}$, Mingtian Wang ${ }^{1,2, *}$, Yuan Yang ${ }^{1}$, Yongkang Luo ${ }^{1}$, Yingwei $\mathrm{Ai}^{3}$ \\ 1 Sichuan Rural Economic Integrated Information Center, Chengdu, 610072, China \\ ${ }^{2}$ Agronomy College, Sichuan Agricultural University, Yaan, Sichuan 625014, China \\ ${ }^{3}$ College of Life Sciences, Sichuan University, Chengdu, 610064, China \\ * Corresponding author, Address: Sichuan Rural Economic Integrated Information Centre, \\ No. 20 Guanghuacun Street, Chengdu, Sichuan, 610072, P. R. China, Tel: +86-28-87364604, \\ Fax: +86-28-87343798, Email: wangmt0514@163.com
}
Abstract: $\quad$ This essay is about agricultural content management system (ACMS) based on project implementation and Internet, which defines; consist of content, system structure and the established foundation of Red hat content management system (CMS) open source council.

Keywords: Agricultural content management system (ACMS), Web Application Framework (WAF)

\section{SUMMARY}

Information-based is the objective trend of the economic and society development in the world today and it is the mark and key to agricultural modernization. With the development of internet, web-based agricultural information-based has already become the main channel of information exchange. Agricultural content management system based on the World Wide Web has to be produced.

Agricultural Content management system (ACMS) contains digital, network of agriculture and its realization. In this way, the organization departments of 
agricultural academy at all levels can use the modern technology of information and communication, realizing the Optimization and Reorganization of agricultural organization structure and workflow on network. Breaking the limitation of time, space and individual departments, it provides all-around management and service to the society with efficiency, quality and regularity.

The significance of ACMS is of consequence. It can built new Net-connected model, breaking the traditional isolated office model. It may contribute new concept and practices to have management, operation, services education and training of agricultural academy integrated.

The realization of ACMS refers to many aspects of CMS, the foundation of Web Application Framework, ACL (Agricultural Category List) of ACMS, AMS (Agricultural Metadata Standard) of ACMS, e-AIF (Agricultural Interoperability Framework) of ACMS, the framework showed by information of ACMS, CMS (Content Management System) of ACMS, and the Portals management of ACMS and so on. This essay will give a simple project based on concept and practice of CMS in the IT circle, to discuss the implementation scheme of ACMS.

\section{HARDWARE BASICS OF ACMS WAF}

An ACMS WAF (Web Application Framework) (http://www.redhat.com, 2002) site is a Computer Cluster application system, which is based on one database server, and subjected to several Web servers, and led by Load Balance server. ACMS site demands to offer 24 hours non-stop service with agricultural management, information communication and application. That is to say, Intranet should satisfy the need of agricultural informative communication and various public services. Therefore, it has to introduce Computer Cluster technology for hardware basics of ACMS. Below is the realization of it:

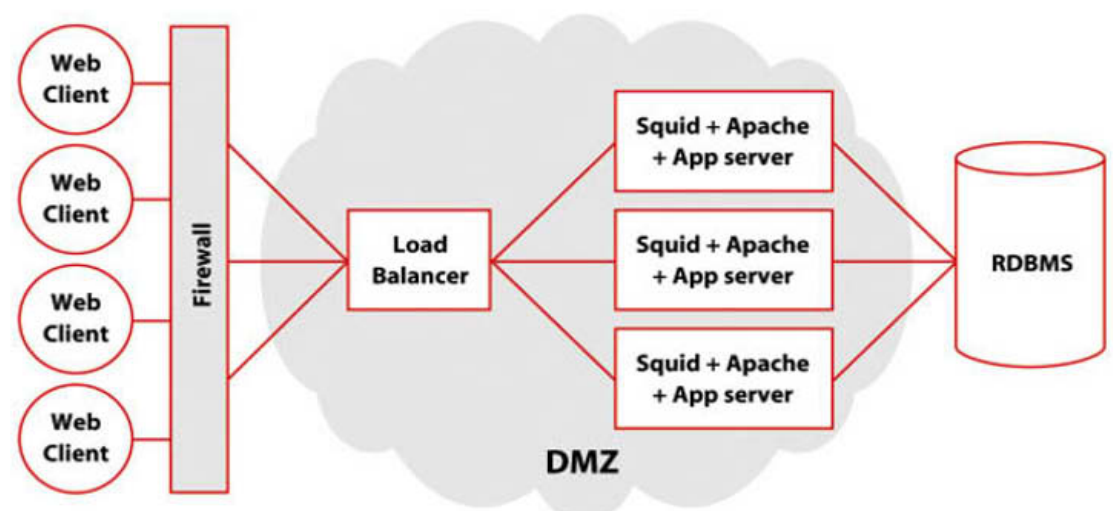

Figure 1. The typical hardware and operational system scheme under Red Hat WAF 
A Load Balance receives the request of all Web client-sides, and selects one Web App Server to comply with the request of client-side according to the running state of Front-End Servers.

In order to relieve the stress of Database Server in Web App Server, the Object Cache based on Squid in Apache Web Server is introduced, so as to solve the bottle-neck problem of Database.

At least 2 front-end Web Servers based on Apache Web Server are in convenience to comply several Virtual Webs on one IP.

A stand of Database Server apply to save operation, service and management data.

The essay only lists the hardware basis under the significance of ACMS WAF, but not to take e-AIF of ACMS into consideration. One reason is to avoid the great length, the other is that e-AIF of ACMS is the author's ideal, but no practice. Finally, it prefers to lay emphasis on the key point in the realization of ACMS.

\section{WAF (WEB APPLICATION FRAMEWORK) OF ACMS}

WAF (Web Application Framework) is not only the basis of ACMS, but also the abstract of all kinds of Web applications. It should follow the principle of open source code, and based on Database, Cross-Platform, and safety, extensible, capable of adapting to the need of various client terminals (e.g. PC, PDA, Mobil-phone, and numerical TV).

The reason why it follows the aforesaid principle is that it saves the cost of Software development and application, and it is also in line with the universal open source and become one of the members in the revolution of open-resource software, and it makes to spread quickly in industry, and it makes CMS standard to follow certain scales of universal standard, of course, it also insures that CMS proceed without interruption through developing of agricultural undertaking.

According to the aforesaid principle, based on the analysis and comparison to nearly 100 CMS systems, Oracle $10 \mathrm{~g}$ commercial database is selected as foundation, J2EE based and open source Red hat WAF is taken as the application framework to ACMS.

Red hat WAF designed as $\mathrm{N}$ layers model, which separates into presentation layer, domain (business logical) layer, data layer, data model layer. Various applications based on WAF (e.g. CMS-content management system, file management, forum...) design according to the layering model.

WAF basic structure as shown in Figure 2, WAF is a Web application management system based on database application, which is built on operating systems, database and J2EE. Above database and J2EE, is CCM system. Many 


\begin{tabular}{|c|c|c|c|}
\hline \multicolumn{4}{|c|}{ Web Browser Interface } \\
\hline \multicolumn{4}{|c|}{ Redhat Portal Server } \\
\hline $\begin{array}{l}\text { Content } \\
\text { Management } \\
\text { System }\end{array}$ & $\begin{array}{l}\text { Document } \\
\text { Management } \\
\text { For Intranet }\end{array}$ & $\begin{array}{l}\text { Weblog } \\
\text { Management } \\
\text { System }\end{array}$ & $\begin{array}{l}\text { Other } \\
\text { Application }\end{array}$ \\
\hline \multicolumn{4}{|c|}{ CCM Core } \\
\hline \multicolumn{3}{|c|}{$\begin{array}{c}\text { Services } \\
\text { Categorization, Version, Workflow, Alert }\end{array}$} & \multirow{3}{*}{$\begin{array}{l}\text { Presentation } \\
\text { Bepop, } \\
\text { xs } 1 \text {, } \\
\text { jsp }\end{array}$} \\
\hline Permission & $\begin{array}{l}\text { Kernel } \\
\text { User and Grot }\end{array}$ & Management & \\
\hline \multicolumn{3}{|c|}{$\begin{array}{c}\text { Persistence } \\
\text { Object-Relational Management }\end{array}$} & \\
\hline \multicolumn{4}{|c|}{$\begin{array}{l}\text { J2EE Application Server } \\
\text { Caucho resion, Tomcat, Jboss, WebSphere }\end{array}$} \\
\hline \multicolumn{4}{|c|}{$\begin{array}{r}\text { RDBMS } \\
\text { Orac le, PostgreSQL }\end{array}$} \\
\hline \multicolumn{4}{|c|}{$\begin{array}{l}\text { Operation System } \\
\text { Centos Linux, Solaris }\end{array}$} \\
\hline
\end{tabular}

Figure 2. Redhat Linux Web Application Framework basic structure

web-based functions can be achieved on a basis of CCM, including content management, forum, bulletin Board, channel management, theme management and portal management etc.

CCM kernel layer of MAF is completed.

The interaction between database and Java object through successive layers lays a solid foundation for extensible, integrated, and congruity of system. That is to say, users need not to tangle with database directly, but to comply UDCT (User Define Content Type) in database. For example, in order to comply Web application of Doppler radar puzzle, it completes UDCT of puzzle in CMS based on Web application, without ever needing to write Java code and SQL Create Table Script.

Security realization based on Web application. That is to say, member, group, role and authorization are the basis of WAF, and every domain object example works in its own scale of security.

Basic Web services realization. That is, WAF regards version control of data item, workflow control, Category list management, to inform users group by bulletin, to alarm to assigned users as basic Web services, no duplication of effort of research staff. 
Presentation and alternation of Domain object. XML, XSL, JSP are the necessary technology to present data item of database. Bepop is also Mark Language to meet XML standard, which is not only to present Web information, but also to transfer the information of event and session between servers and client terminals. The services supplied by ACMS could adjust different client terminals and language environments because it mainly uses XSL technology.

\section{AGRICULTURAL CATEGORY LIST OF ACMS}

ACL (Agricultural Category List) is the start and end of information organization and category. If it prefer to application of ACMS, it should built security certification system, work standard, and quality system to be up to the demand of Internet. Content management and service of ACMS essentially follow as hierarchy category for clue. It particularly comes down to tabulation and management of agriculture terminology list, agricultural category list, domain list, navigation list and loose-leaf folder list.

Agricultural terminology list is the basis of information organization, communication and ACL. It defines the scope of database and technology standard.

Domain list is the top category of Agricultural terminology list.

$\mathrm{ACL}$ is tree-category of Agriculture terminology list.

When some terminologies are both belong to A and B, ACL support linkcategory concept. For example, civilization contains education, science and technology also contains education, in this way, science and technology is set for the link contained education.

A database admits of several LACL (Local Agricultural Category List), which is aimed at different areas, various departments, different services and management. LACL and ACL can set up mapping relationship. Generally LACL is to further detail of ACL.

Navigation list is URL of ACL.

Folder list is another form of sorting assigned items by users. Different from ACL, every file in folder list corresponds to different access-rights and security precautions mechanism. The particular dividing regulation is determined by soft science achievements.

\section{AMS (AGRICULTURAL METADATA STANDARD) OF ACMS}

Metadata is first of all data about data, and then it is about the frame information of resources. The metadata standard of ACMS is e-AMS, whose design objective is to adjust to any content and resource in ACMS, and Web site and data recorded management of ACMS. E-AMS complied with Dublin core 
standards. Besides its own elementary metadata, the support of MCL and ADSC is also required (Agricultural Data Standards Catalogue). E-AMS is the component of E-AIF.

E-AMS is mainly applied to search for the information and resources on agriculture for the public and agricultural staff.

$\mathrm{ACL}$ and the element subject category in e-AMS are corresponding.

There will be an assay especially on e-AMS.

\section{AIF OF ACMS}

Agricultural information is the resources within the agricultural department, but also social assets, which is just like fuel for the national knowledge economy. It should be shared by both the departments and other members in the society. Because of ACMS based on Web, distributed Web service and Database are inevitable features. How do we ensure the consistency of the web content? How do we complete the information exchange among each database? How do we ensure all levels of agricultural organizations follow the regulations admitted by inner department and the society, when agricultural information is shared to public?

E-AIF (Agricultural Interoperability Framework) is the standard of information exchange followed by ACMS members. It makes a seamless linkage to agriculture knowledge, services and management in agricultural departments within or cross provinces. At the same time, It offers a more accordant and broader service mode.

With the need from strategic management, e-AIF selects XML and XSL as the core standards for data integration and presentation data. E-AIF also defines and applies e-AMS, which provides quick queries on agricultural information and resources.

E-AIF structure is as shown in Figure 3. E-AIF on top level is Framework, which is responsible for formulating and action of a higher level policy, system and standard. E-AIF on second level is the exact approach and realization of

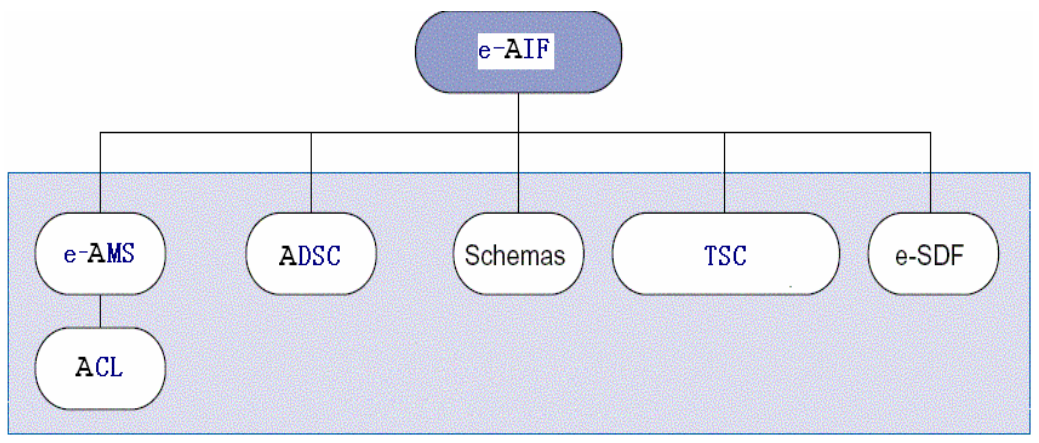

Figure 3. AIF structures 
Framework, in other words, the realization content of e-AIF standard, which are e-AMS, ADSC (Agricultural Data Standards Catalogue), XML Plan Schemas, TSC, e-SDF (Service Development Framework).

It is presentation below that e-AIF is framework. There will be an assay especially on all items on the second place.

The main line and principle of e-AIF Framework

Completely follow by Internet and World Wide Web standard

Make XML the chief standard of data integration

Brower is taken as the main interface with other interfaces as additional

Add metadata to agricultural information resources

Develop e-AMS based on Dublin Core Model

Develop and maintain the authority of ACL in all-level administrations

Develop and maintain the authority of e-AIF in all-level administrations

Key evaluated indicators of e-AIF standard

Interoperability: Capability of standard in Net Link, data integration, e-service and content management among systems.

Market support: Capability of standard to win mass support in the market in order to reduce expenses and risk of agricultural department.

Scalability: Capability of standard can be adjusted to system extended. For instance, it can adjust to the expansion of quantity of data, work disposed and quantity of users.

Openness: Capability of standard to be general applicability.

Main application scope of e-AIF standard

Between Chinese agricultural and citizens

Between Chinese agricultural and world business

Among Chinese agricultural organizations

Between Chinese agricultural organizations and the other world agricultural organizations

All new research systems of agricultural organizations and information exchange within the listed above, e-AIF standard is necessary.

E-AIF standard can be adjusted to all present and future channels such as Internet, digital television, WAP phone, PDA and so on.

The technology line is related to at least 4 parts, which are Net link, data integration, eservice and content management.

The realization content of $e$-AIF standard

$X M L$ schemas of ACMS

E-AMS of ACMS

E-Services Development Framework

In this essay, e-AIF framework is rough, and it does not contain the way of practice and management of XML schemas of ACMS, the organization and management of e-AIF etc. A special thesis is planned to write to discuss these issues.

\section{INFORMATION PRESENTED FRAMEWORK OF ACMS}

In the ideal situation, agricultural department information makes the seamless linkage according to public's habits and the operational rules. That is also the start point of the information presented framework model and technology support of building the unified external image of ACMS. 
The CMS Website bases on web technology. It not only has the standard recognized by all the levels, which contain affairs category, sub-category, and sub-sub-category, but also the navigation standard which is in accordant with the Web browse habit.

The CMS focus on the information framework model on the programming of information framework, information displayed template, overall page element, inquiring, landing, dictionary, site map etc.

The basic contents of information framework are:

\begin{tabular}{ll}
\hline Title & Explanation \\
\hline Category Bill & $\begin{array}{l}\text { It is the start point of information framework. Generally, the first } \\
\text { ten categories are also the basis of navigation guide. }\end{array}$ \\
Top Category & $\begin{array}{l}\text { It defines a general category over subordinate department } \\
\text { categories, and abstracts the same category, as for the public to } \\
\text { browse information on different Webs among different } \\
\text { departments. }\end{array}$ \\
Top guidance & $\begin{array}{l}\text { A set of guide label placed on the top of every page. } \\
\text { Z }\end{array}$ \\
List & $\begin{array}{l}\text { It is information inquiring based on list like Yahoo, BBC. It } \\
\text { resets Category Bill. }\end{array}$ \\
A set of Public page & $\begin{array}{l}\text { The page element and style followed by all subdivisions. } \\
\text { element }\end{array}$ \\
A set of URL & $\begin{array}{l}\text { A group of standardize resources location, by which the public } \\
\text { only need to enter URL to look for the kind of information. }\end{array}$ \\
\hline
\end{tabular}

The main function of the information display model is to make the web inf. (information) not only used in the PS, but also in the digital TV, mobile phone and PDA. The CMS mainly uses XML and XSLT technology to assure the information could be exchanged from one platform to another.

Every spec of XSL works with corresponding inf. model.

The element of overall page is made up of common tools on the top of page, category of page top, page position indicator, navigation on the left, page bottom, and related link information on the right.

\section{ACMS (AGRICULTURAL CONTENT MANAGEMENT SYSTEM)}

CMS (Content Management System) is the start point of agricultural content management and the core part of the whole system. CMS makes creation and processing in all-levels agricultural organizations be in accordant with each other, hence sustainable and extendable. The updating of agricultural information is not limited by the place of work, because CMS allows the individual to create and maintain the content. In addition, management activities 
focal on content management improved the capabilities from knowledge sharing and communication in organizations, and improved the work efficiencies, removed the communication barriers.

Generally, CMS contains creation and practice of content type, version control, file management, Workflow managing, life cycle of data item, people managing, security management, loose-leaf folder management, file style definition, page model management, category management, file nationalization management, and information exchange with other CMS by RSS.

Content type is the basis of communication and work on the Internet. Because of content type management (create, modify, delete) being contained by Red hat CMS, therefore it is easy to extend to agricultural service system, resources agricultural service system, agricultural management system, financial system, and human resources system and so on.

Version control is completed with managing of work process.

File management is completed with creation, modification and deletion of various content types, and it contains all kinds of editors such as MS Word.

Workflow managing regulates a series of stages similar to creation, modification, deletion, check-up, and the publishing of contents.

Life cycle of data item regulates save time of data item in database.

People managing contain the assigning of roles and security authority of members besides creation, deletion and modification of members.

Security management contains role, user, group management and authorized management.

Folders management contains creation, deletion, modification, and security management of file and sub-file (hierarchically authorized to work group and staff).

Category management determines that the clues of CMS are terms and the classification of them. The determinate term is correspondent with the type of the determinate content. A category contains one or more terms. Every category and terminology has its own URL label.

\section{PORTALS MANAGEMENT OF ACMS}

Generally, ACMS is made up of several sub-Webs. Every sub-Web has its own theme page which is consisting of several xsl, css, and jsp. The portals management model realizes developing, testing and releasing of various theme pages, and applies it to the allocation of sub-Web.

\section{TESTS}

Website for 96999 Call Center: http://96999.scnjw.gov.cn

Website for Meteorological Bureau of Sichuan, China: http://www.scqx.gov.cn 
They are all bases on Redhat WAF and CMS. They can also be viewed as tests for the systematic construction of ACMS. Steps are as follows:

It forms as the working group contained Sichuan Provincial Agricultural Academy, city-level, and county-level branches. The service object is the public;

Install Java environment, Oracle date base, set Apache server, set Resin, install Red hat CMS;

Establish terms, terms category and navigation address;

Confirm labor division. Establish members, assign roles and authority;

Build content type, content life cycle and workflow;

Build homepage and theme-page template.

Sichuan Provincial Agricultural Website has been completed according to WAF and CMS technology, and optimized on that base. The test shows that ACMS systems engineering in each information center is practicable.

At present, the system has been applied in the construction of Sichuan Rural Economic Information Net with 6000 working staff and English version of it, Sichuan Meteorological Intranet. It can be seen that those websites share one Database and work in different sections of CMS.

\section{DISCUSSION}

The origin of ACMS: Through the study of e-government, many aspects of e-government can be applied in the agricultural information management in the terms of information management. Therefore, it gets the concept of Agricultural Content Management System.

The relationship between technology and strategy: When construction of ACMS implements, first of all, it has to face the relationship between technology and strategy. The meaning of "Science and Technology is the First Impetus" has to be reviewed. Although ACMS solves a series of technology problems, it is the basis of founding and practicing the strategy. In other words, the technology determines the management regulations, methodologies, service functions and implementation of strategy. On the other hand, strategy both affects and boosts the development of technology. The application of ACMS construction is up to the orientation to strategic development.

The relationship between technological engineering and soft-science: When implementing the construction of ACMS, there is a problem of coordination between technology and management. ACMS is involved with establishment and implementation of a large amount of standards, terms, management regulations, workflow and etc. On one hand, administrators should understand the terms in ACMS and form a complete management system. On the other hand, obstacles in management and trainings should be cleared in the process of technological realization.

Formation of overall objectives: There are three steps in the construction of ACMS. Firstly, the development and application of technology are under the basis of open source code Web CMS. Secondly, it builds standards and guides 
for Web site of province-level ACMS. Finally, it builds e-AIF (Agricultural Interoperability Framework). The overall objective is to found a complete set of nationwide Web agricultural standard and general framework.

Tasks in the near future: The construction of ACMS cannot be achieved in one move, but a long and tough process of spiral. Application tests and technology development with CMS as the core will be carried out in the near future. Meanwhile, it should be paid close attention to the establishment of standards with category as clue. The most complicated thing is to build e-AIF before which technology guide should be realized.

\section{REFERENCES}

Related to the information of building plan and standard of electronic affairs, refer to http: //www.govtalk.gov.uk

Related to the information of development of CMS and OpenCMS, refer to http: //www.opencms.org

Related to the information of Red hat CMS, WAF and Portal Server, refer to http: //www.redhat.com/ccm

Related to the information of technology realization of APLAWS and CMS, refer to http: //aplaws.sourceforge.net 